\title{
Feasibility Analysis of an Islanded Microgrid in Tohatchi, New Mexico Using HOMER Pro
}

\author{
Peter Jenkins, Aditya Chandrashekhar Sonar \\ Department of Mechanical Engineering, University of Colorado, Denver, USA \\ Email: Peter.Jenkins@ucdenver.edu,AdityaChandrashekhar.Sonar@ucdenver.edu
}

How to cite this paper: Jenkins, P. and Sonar, A.C. (2020) Feasibility Analysis of an Islanded Microgrid in Tohatchi, New Mexico Using HOMER Pro. Energy and Power Engineering, 12, 357-374. https://doi.org/10.4236/epe.2020.126022

Received: May 16, 2020

Accepted: June 21, 2020

Published: June 24, 2020

Copyright (อ 2020 by author(s) and Scientific Research Publishing Inc. This work is licensed under the Creative Commons Attribution International License (CC BY 4.0).

http://creativecommons.org/licenses/by/4.0/

\section{(c) (i) Open Access}

\begin{abstract}
Microgrids are becoming more popular in areas where there is still no connectivity to the main grid largely due to their remote geographical location. This paper focuses on the feasibility analysis, using the HOMER Pro simulation program, of an islanded micro-grid for the Navajo community in Tohatchi, New Mexico using different energy mixes of a Photovoltaics (PV) system, a Wind Energy system, a Battery Energy Storage System (BESS) and a Diesel Generator. The Net Present Cost (NPC), and the Levelized Cost of Electricity (LCOE), were the two crucial economic factors considered. Through the analysis, the system with the PV, wind turbines, battery, and a diesel generator was found to have the lowest LCOE and NPC. There was a reduction of $75 \%$ in the costs of the combined system as compared to the diesel-only base case. Also, this combined system provided the minimum emission levels. The analysis suggests that the integration of renewable energy using microgrids to help the access of energy for rural areas was possible. The analysis could very well be extended to any other community by considering the wind and solar resources present at that location.
\end{abstract}

\section{Keywords}

Renewable Energy, PV, Wind Turbine, Microgrid

\section{Introduction}

Over half of the world still has no access to electricity. Many of these places are in geographically remote locations where either the main grid cannot penetrate, or it takes years for the main grid to get approved by the higher authorities owing to financial restrictions. Microgrids, which are mini power grids, can help solve these problems [1]. 


\subsection{Concept of a Micro-Grid}

A microgrid can be defined as a combination of loads, energy storage devices, distributed energy resources (DERs) such as photovoltaics, diesel generator, wind turbines, natural gas power plants, etc. along with a central monitoring system which is responsible for managing the load response. It can operate independently as well while being connected with the main grid. One of the notable advantages of a microgrid is that it can achieve high renewable energy penetration. Hence, for places where it is hard for the main grid to penetrate, the use of clean energy sources in the form of a microgrid can be proposed. As the name suggests, microgrids operate on lower voltage levels as well as have a smaller size compared to the conventional grid. Another advantage of a microgrid is it can be custom sized based on the load demand. One major setback while considering the installation of a microgrid is to justify the cost of the system as compared to conventional coal-fired power plants or diesel generators (Figure 1).

\subsection{Components of a Microgrid}

The main components of a microgrid include:

- Electric load-This is the load that is to be met by the microgrid system. The electric load can be further divided into critical loads and non-critical loads. The average electricity demand to be met plays an important role in the substantial of the entire system.

- Battery energy storage system (BESS)-Storage devices have recently become an integral part of microgrids. To a large extent, for islanded microgrids, it has become very necessary to have backup storage devices since complete reliance on renewable energy sources is not possible due to their unpredictable nature. Excess energy produced can be stored in energy storage systems during intervals of high energy penetration and can then be used to meet high energy demand or during times when there is very low energy penetration.

- Distributed energy resources (DERs)-The distributed energy resources range from diesel generators, renewable energy sources like solar and wind to natural gas power plants. Most of the islanded microgrids harness wind and solar energy in combination with battery storage and diesel generator or natural gas power plant based on the geographical location and the renewable energy penetration of the region.

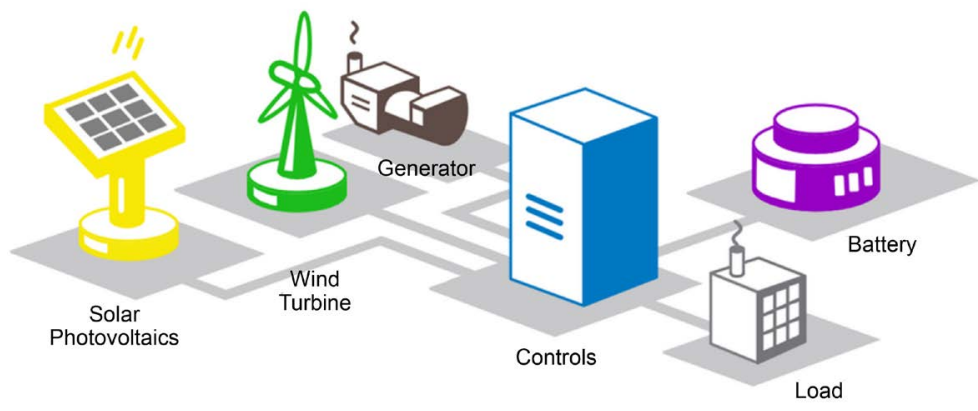

Figure 1. Structure of a microgrid. 
- Converter-A converter is an integral part of a microgrid system. It is responsible for converting DC to AC and vice-versa. It is equally responsible for the conditioning of power therefore making it suitable for end-user applications.

- Controller-The controller is the brain of a microgrid. It controls the smooth functioning of the entire system and for maximizing the power output. Once a microgrid controller is programmed according to the needs of the user, it automatically evaluates different energy scenarios and acts accordingly. It is responsible for the daily assessment of how the energy demand should be met, when the energy from the battery should be utilized, when the backup generators should be turned on, etc.

\subsection{Phases of Developing a Microgrid}

The process of developing a microgrid was divided into three phases [2].

- Phase I: Feasibility/Conceptual design

- Phase II: Detailed design drawing/Finalizing components based on their performance and user requirements

- Phase III: Final design drawing and site layout

This study achieves the following:

1) Proposes renewable energy-based islanded microgrid by assessing its techno-economic feasibility.

2) Minimizes the levelized cost of electricity using the best combination of energy mixes and justify the high capital cost as compared to the conventional grid.

3) Models and predicts the performance of the system using a simulation tool-HOMER Pro.

4) Alleviates and improves the electricity reliability issues for the village of Tohatchi.

According to NREL's research on cost analysis of microgrids in the USA, community microgrids are found to have around $\$ 2.1$ million/MW of DERs installed (Figure 2).

\subsection{Simulation Tool-HOMER Pro}

HOMER Pro was selected as the simulation tool to check the feasibility analysis and performance of the system. HOMER Pro, which was originally developed by the National Renewable Energy Laboratory, is the world's best simulation tool for microgrid analysis. It has quickly become the measuring stick for microgrids due to its ability to determine the best dispatch strategy of the distributed energy sources along with its ability to achieve the best combination of energy mixes for a system. HOMER Pro can analyze hourly load data for the whole year and strategize to minimize the cost of electricity. It also provides the flexibility to design the system both in the islanded mode as well as in grid-connected mode. It is also capable of doing a sensitivity analysis based on any changes in the input parameters like the fuel price, percentage of renewable energy penetration, etc. (Figure 3). 


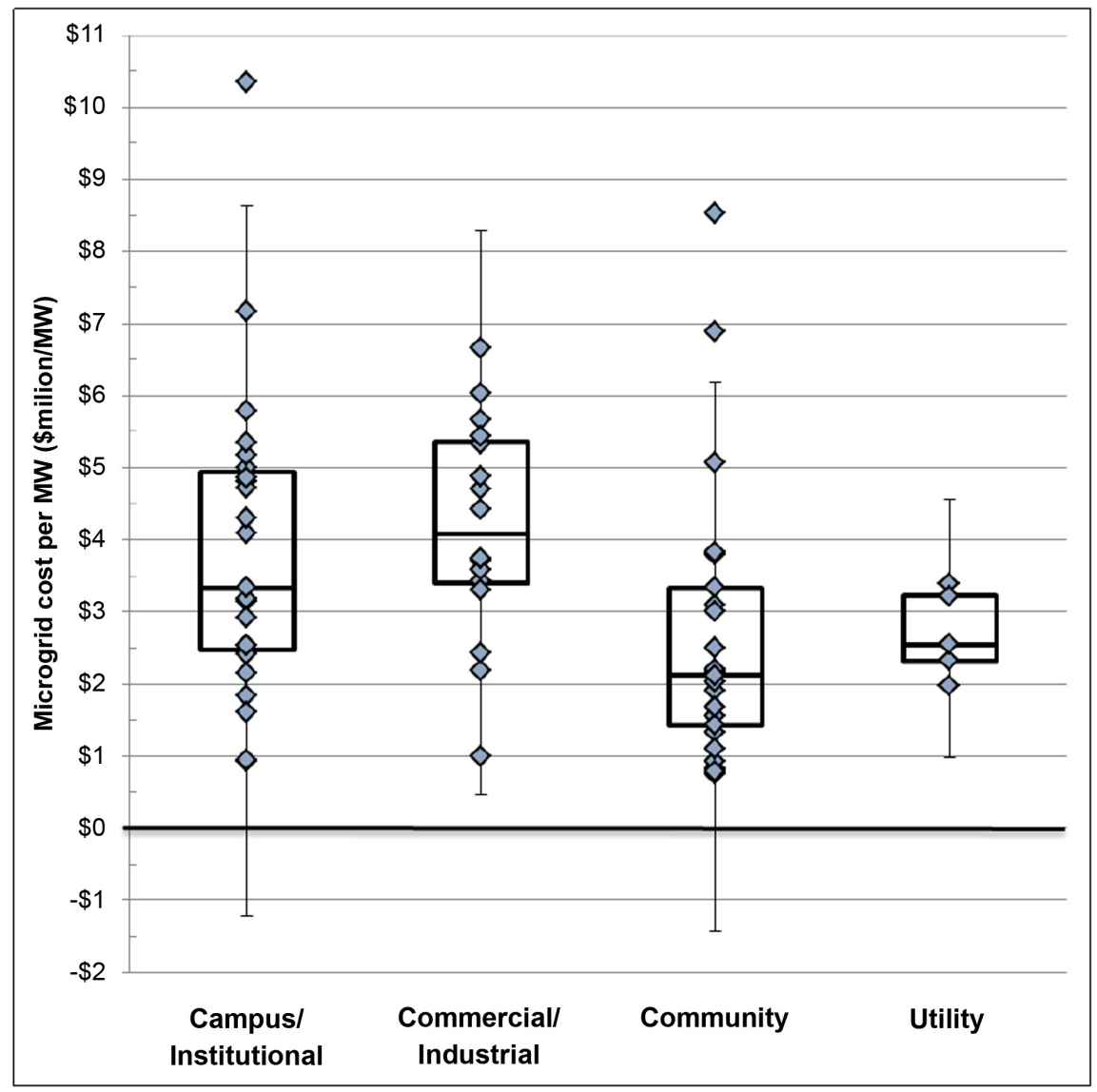

Figure 2. Microgrid costs based on the market segment [3].

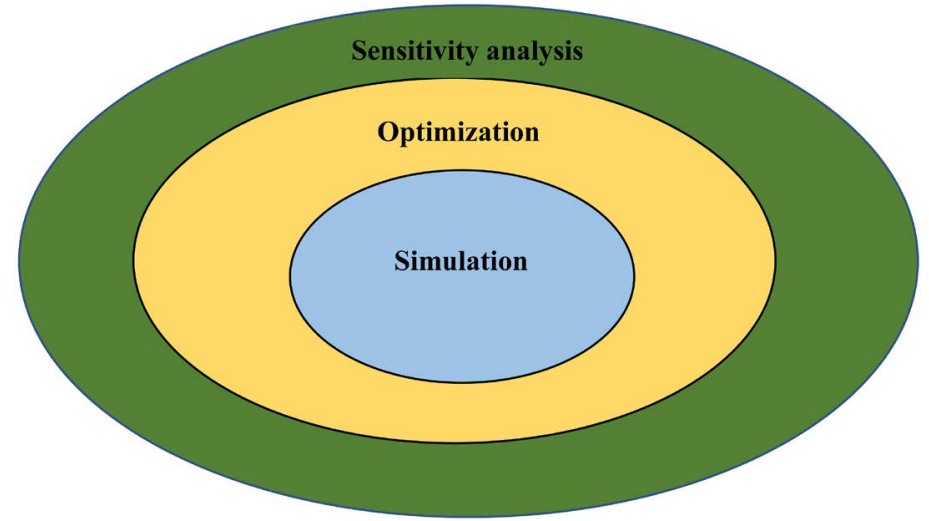

Figure 3. Capabilities of HOMER Pro simulation tool [4].

\section{Data Collection}

After the identification of the primary objective to implement a microgrid, it was necessary to identify the available energy resources and the meteorological data for a location to justify the feasibility of installing the system.

\subsection{Community Study}

Tohatchi, which is a part of the Navajo Nation, is a remote village in McKinley 
County in New Mexico. It has a population of about 1500 people residing in two major communities with the number of houses in the communities totaling to approximately 250 . The location of the village is $35^{\circ} 51^{\prime} 1 " \mathrm{~N} 108^{\circ} 45^{\prime} 3 \mathrm{l} \mathrm{W}$ and it lies at an altitude of 6447 feet above the sea level (Figure 4).

\subsection{Solar Energy Potential of the Location}

According to the NREL meteorological database, Tohatchi was fortunate to receive an abundant amount of sunlight throughout the year and receives average solar radiation of about $6.40 \mathrm{kWh} / \mathrm{m}^{2} /$ day. It receives around 12 hours of sun hours per month on an average with peak months being April, May, June, and July.

\subsection{Wind Energy Potential of the Location}

Owing to its geographical location and its altitude, Tohatchi has a steady availability of wind speed. The wind speed varies from $3.80 \mathrm{~m} / \mathrm{s}$ to $10.90 \mathrm{~m} / \mathrm{s}$ throughout the year whereas the annual average wind speed is about $6.65 \mathrm{~m} / \mathrm{s}$ [5] (Figure 5 \& Figure 6).

\subsection{Electric Load Profile}

Since exact details of the load profile of the community were not available, the load data was taken to be the average load consumption of a house in New Mexico which is approximately about $650 \mathrm{kWh} /$ month. A generic community load profile for the whole year was chosen from HOMER Pro. Using this, the average

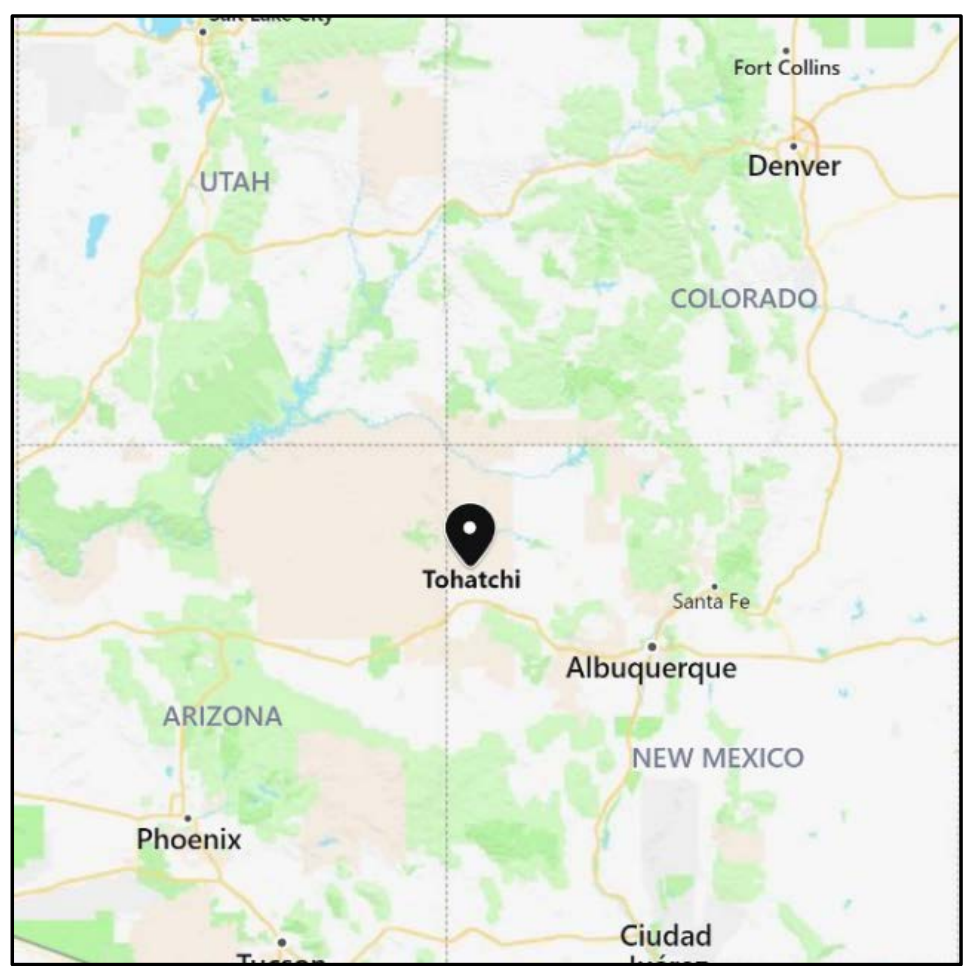

Figure 4. Geographical location of Tohatchi [Source: Bing Maps]. 


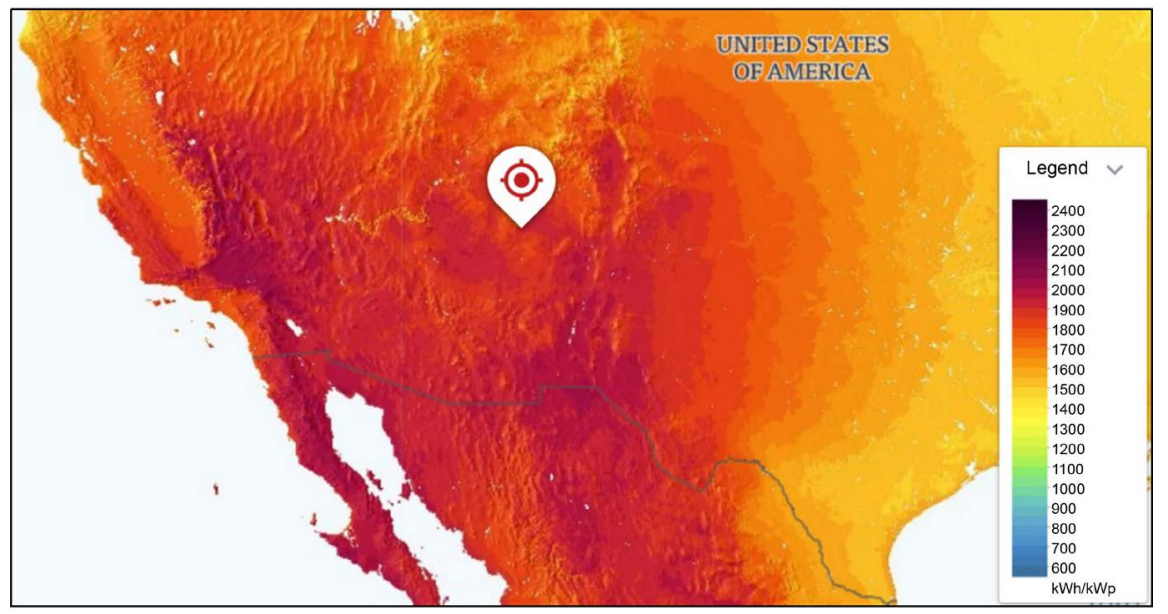

Figure 5. Photovoltaic resource map of the United States.

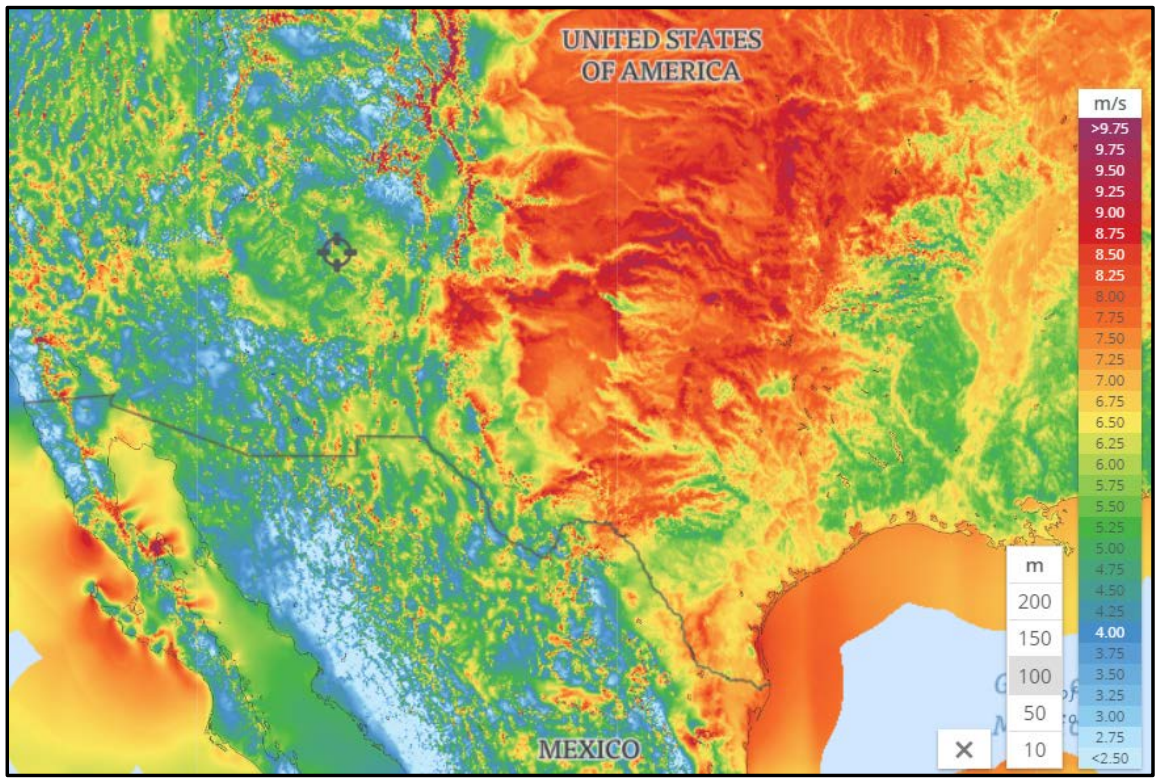

Figure 6. Wind resource map of the United States.

consumption of the whole community per day, considering 250 houses, was $5416.67 \mathrm{kWh} /$ day. The load profile was scaled in HOMER Pro according to the average consumption of the community (Figure 7).

\subsection{Feasibility Check}

While designing any system it is important to carry out a detailed analysis of the available resources to know that the system will perform according to the needs of the user during its lifetime. For this renewable energy system, the minimum amount of wind speed and the minimum amount of solar irradiation required to generate electricity were checked against the meteorological data obtained from the installation site.

1) The amount of energy produced using wind power was directly proportional to the cube of the wind speed $\left(E_{\text {wind }} \propto v^{3}\right)$. Consequently, wind speed becomes an 


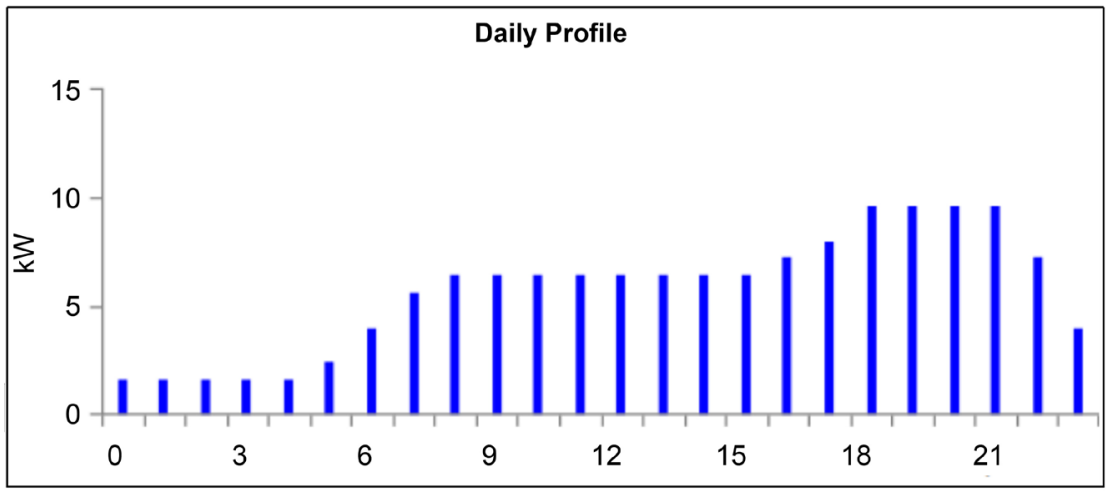

Figure 7. Daily load profile of the community [4].

important criterion that needs to be met while thinking to install a wind farm to gain a good return on investment. The average wind speed available throughout the year in Tohatchi was found to be $6.65 \mathrm{~m} / \mathrm{s}$ against the minimum required wind speed of $6.50 \mathrm{~m} / \mathrm{s}$ to generate electricity. As follows, the installation of a wind turbine was considered feasible in the renewable energy mix [5].

2) As for solar energy, the minimum amount of solar irradiation required per day from the installation site was greater than or equal to $3.50 \mathrm{kWh} / \mathrm{m}^{2}$. The average solar irradiation of Tohatchi per day was found to be $6.40 \mathrm{kWh} / \mathrm{m}^{2}$ which makes it viable for photovoltaic installation. Since solar energy is a major investment and hence considering all the previous points, a solar photovoltaic system was proposed for design and installation in Tohatchi while also keeping in mind the financial feasibility (Figure 8 \& Figure 9).

\subsection{Meteorological Data}

The meteorological data for the location was collected from the National Oceanic and Atmospheric Administration (NOAA) [6] (Figures 10-12).

\section{System Components}

\subsection{Photovoltaic}

The solar panels chosen for this study were manufactured by SunPower. The model was SunPower X21-335-BLK. The solar modules had an efficiency of 21\% and their lifetime was 25 years. The operation and maintenance cost of the module was taken to be $\$ 10 /$ year. The capital cost of this module was $\$ 330$ each. The technical specifications of the module are presented in Table 1.

\subsection{Battery Energy Storage System (BESS)}

Two battery energy storage system types were considered in this study:

- Tesla Powerwall 2.0-The Tesla Powerwall 2.0 battery can provide backup power for 1.9 hours. The depth of discharge of these batteries was $100 \%$ and they have a lifetime of 10 years. The cost of one battery was $\$ 6500$ including installation cost. The operating temperatures of the battery are between $-20^{\circ} \mathrm{C}$ to $50^{\circ} \mathrm{C}$. 


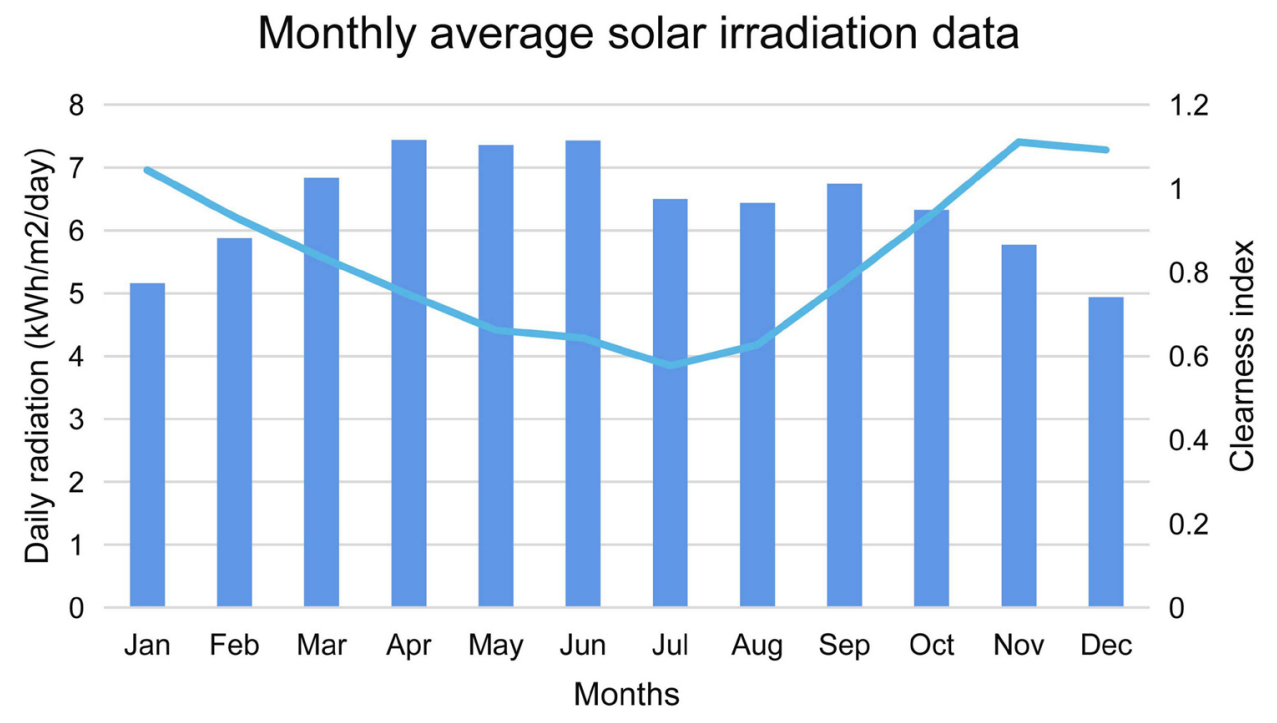

Daily radiation $\left(\mathrm{kWh} / \mathrm{m}^{2} /\right.$ day $)$ Clearness Index

Figure 8. Monthly average solar irradiance profile.

\section{Average wind speed $(\mathrm{m} / \mathrm{s})$}

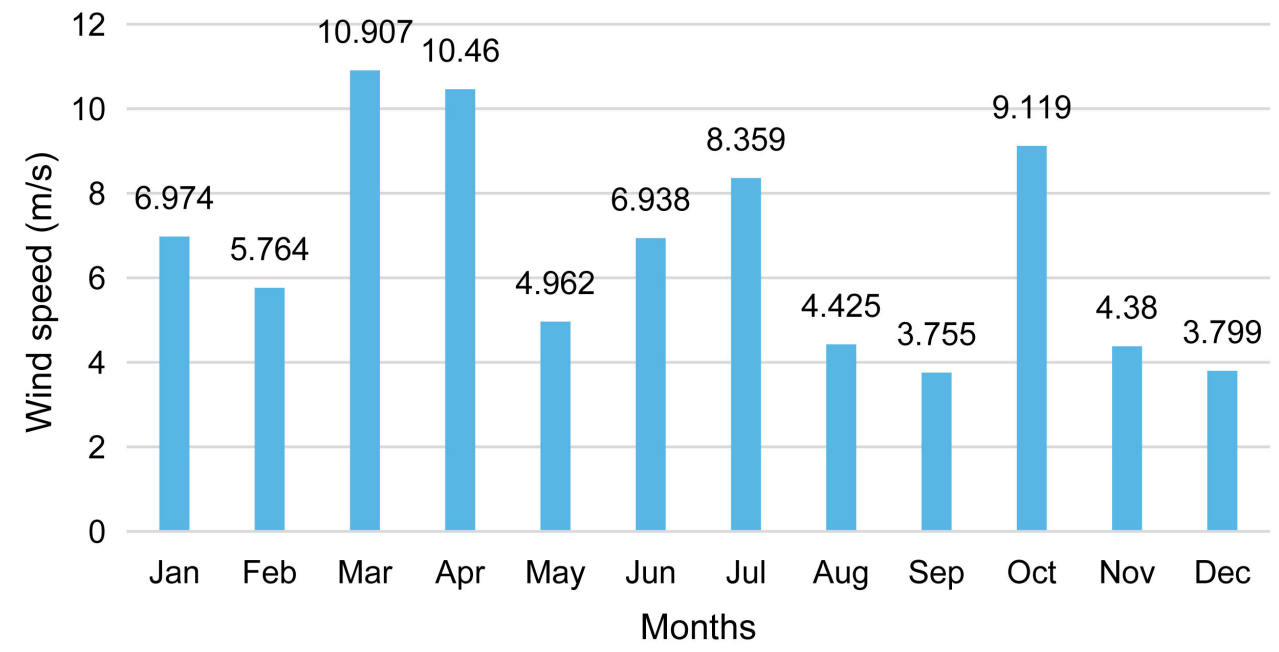

Figure 9. Monthly average wind speed profile.

Temperatures $\left({ }^{\circ} \mathrm{C}\right)$

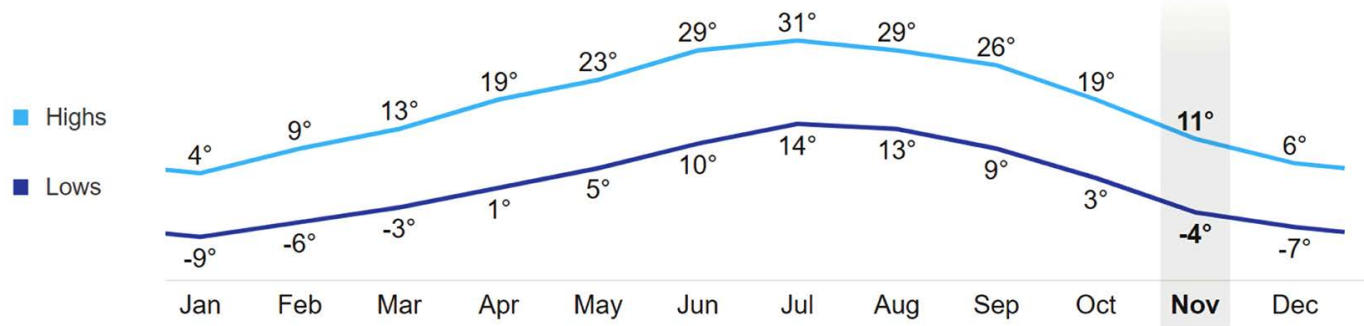

Figure 10. Variation in temperature throughout the year [6]. 


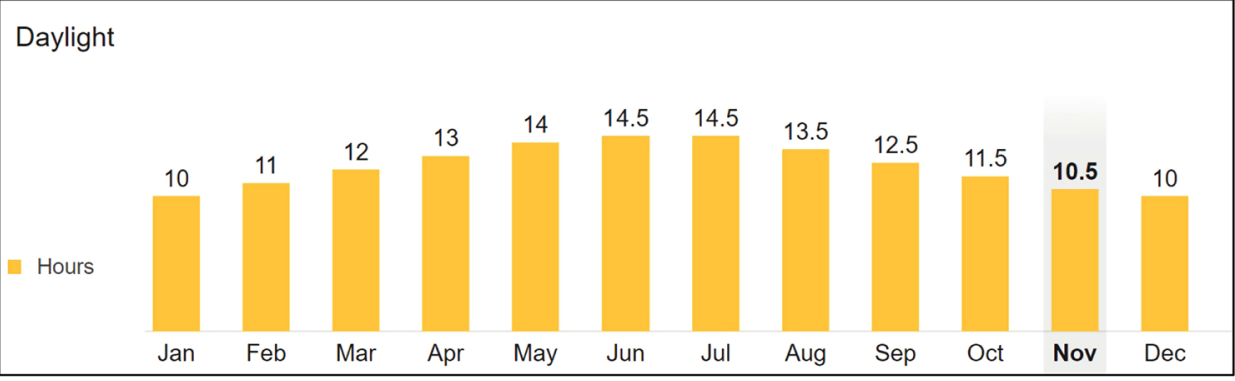

Figure 11. Variation in hours of daylight throughout the year [6].

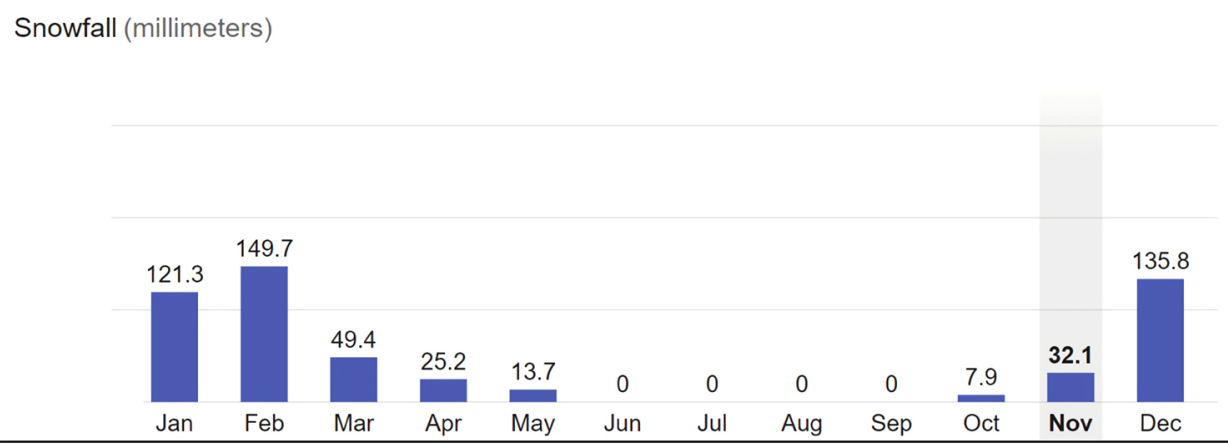

Figure 12. Variation in snowfall throughout the year [6].

Table 1. Module specifications.

\begin{tabular}{cccc}
\hline Sr. no. & Parameter & Units & Values \\
\hline 1 & Maximum power $\left(\mathrm{P}_{\mathrm{mp}}\right)$ & W DC & 335 \\
2 & Nominal efficiency $(\eta)$ & $\%$ & 21 \\
3 & Temperature coefficient & $\% /{ }^{\circ} \mathrm{C}$ & -0.300 \\
4 & Operating temperature & ${ }^{\circ} \mathrm{C}$ & 43 \\
5 & Panel type & - & Flat plate \\
\hline
\end{tabular}

- Redox flow battery-These batteries have recently started gaining prominence due to the improvement in their efficiency and their working capabilities [7]. Redox flow batteries store energy by using two electrolyte solutions which are stored in two separate tanks. A cell stack contains several cells in series or parallel to allow for the electron transfer to take place. Each cell has an anode, cathode and an ion-exchange membrane which allows for the diffusion of ions while also restricting the electrolytic solutions to mix. The capacity of these batteries was decided based on the number of cells as well as the volume of electrolyte and hence can be custom sized. The main reason why they are gaining prominence is their ability to store energy worth over 6 hours. However, the cost of these batteries was still high which makes them less viable due to financial restrictions.

The BESS was considered to minimize the use of the diesel generator and provide a benefit during the time of low sunshine (Figure 13). 


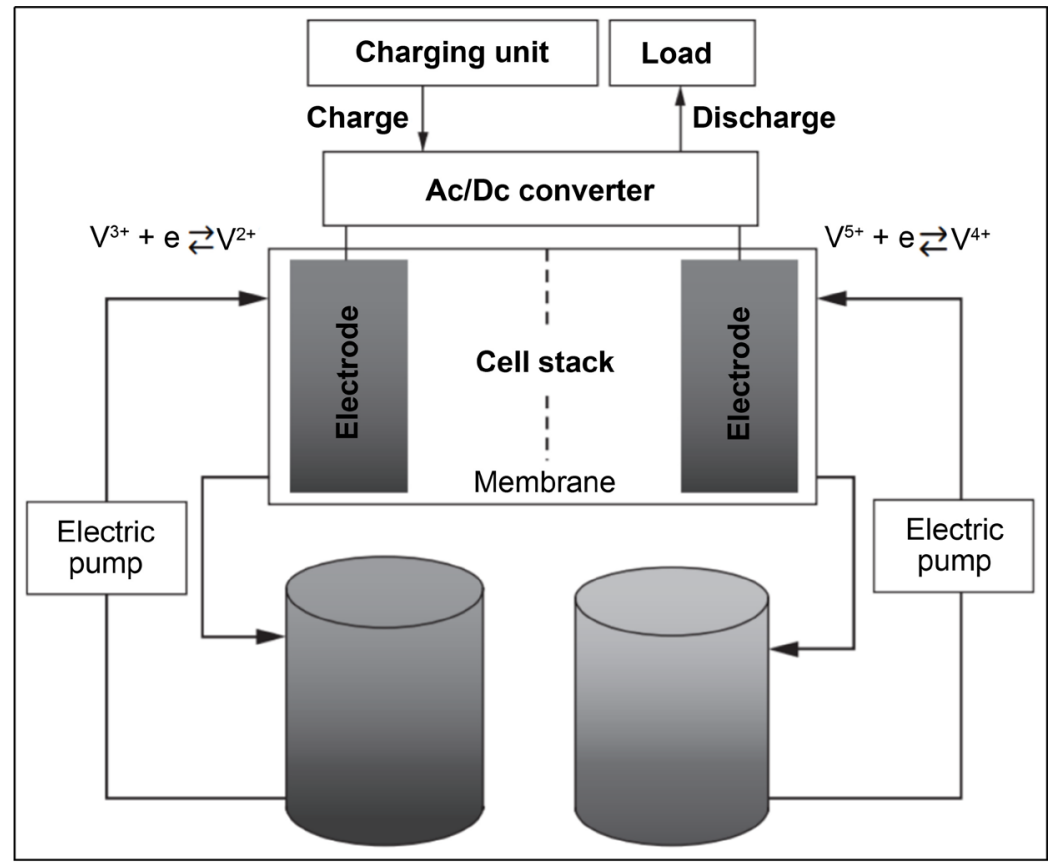

Figure 13. Layout of a generic redox flow battery [7].

\subsection{Wind Turbines}

Bergey Excel S.60 $10 \mathrm{~kW}$ wind turbine were chosen for this study. The cut-in speed for the wind turbine was $2.5 \mathrm{~m} / \mathrm{s}$. The capital cost of one turbine was about $\$ 7400$ including the installation cost whereas the lifetime of these turbines was 20 years. The operation and maintenance cost for the turbine was taken to be $\$ 100 /$ year.

\subsection{Converter and Diesel Generator}

A generic system converter and an auto-size diesel generator were selected for the analysis. The converter usually does not incur any maintenance cost, hence the cost was taken to be $\$ 0 /$ year. As for the diesel generator, the operation and maintenance costs were taken to be $\$ 0.03 /$ hour of operation. Since the cost of diesel constantly fluctuates, the cost of the diesel for sensitivity analysis was considered to vary from $\$ 0.80 /$ litre to $\$ 1.20 /$ litre.

\section{Simulation Results}

To get an optimum configuration of the microgrid, different energy mixes were considered keeping in mind the financial aspects of the analysis. This section will particularly discuss the different designs considered while finalizing the best combination of technology sources for the least cost solution. The results demonstrated are for a sample population of 10 houses.

Table 2 provides a brief pictorial summary of the configuration of all the system architectures studied. D1, which is the base case, uses the diesel generator for the whole year to meet the energy demand.

Table 3 provides a summary of the optimum feasible solutions. 
Table 2. Summary of systems.

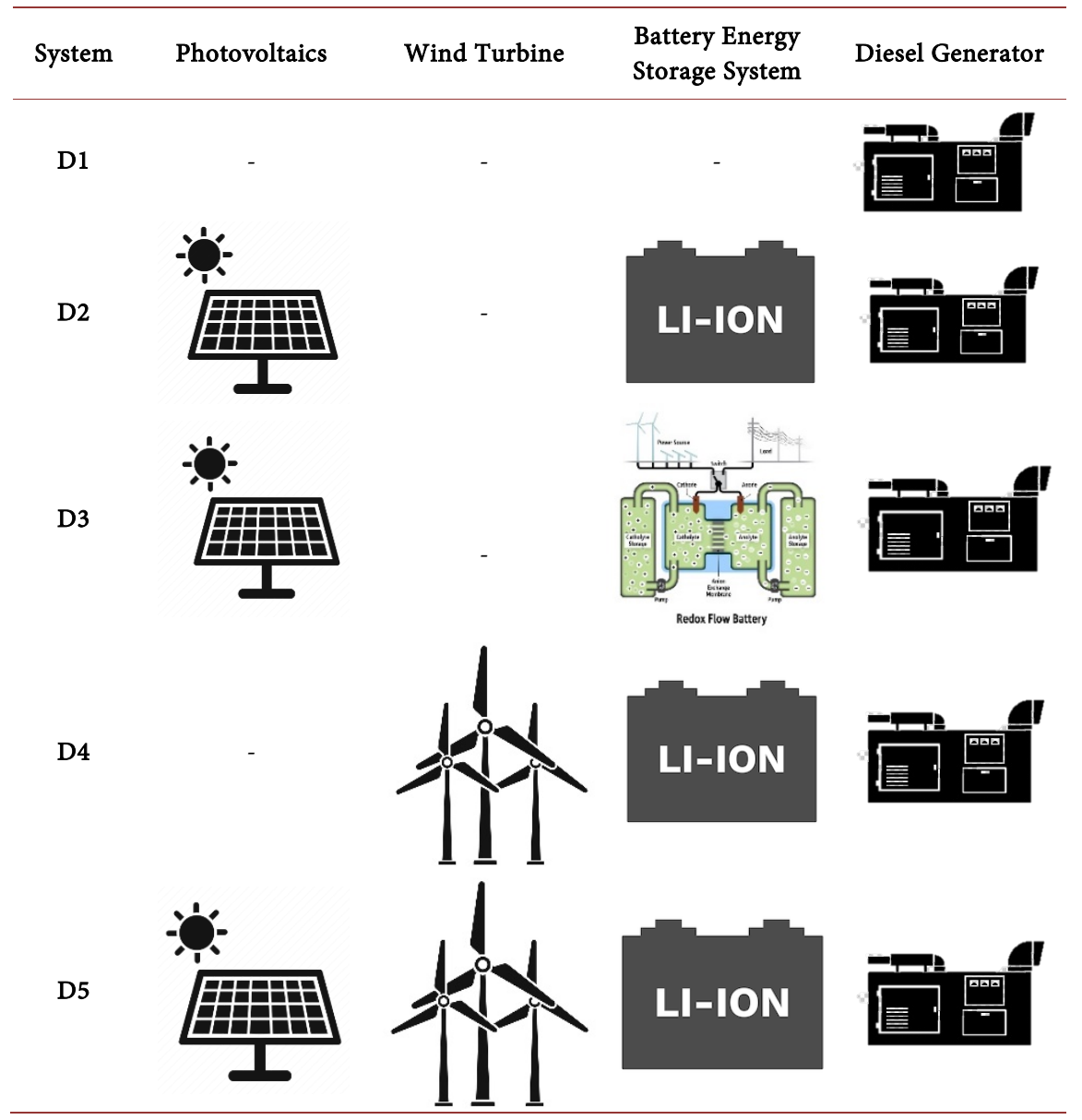

Table 3. Optimization results for different systems.

\begin{tabular}{cccccc}
\hline Design & D1 & D2 & D3 & D4 & D5 \\
\hline PV Array [kW] & - & 46.7 & 48.8 & - & 13.2 \\
Wind [no.s] & - & - & - & 7 & 5 \\
Diesel Gen. [kW] & 34 & 34 & 34 & 34 & 34 \\
Battery [no.s] & - & 10 & Flow bat. & 3 & 3 \\
Converter [kW] & - & 23.1 & 20.7 & 18.8 & 19.5 \\
Ren. Fraction [\%] & - & 93.0 & 90.3 & 78.7 & 83.1 \\
Diesel Fuel [liters/yr] & 39,052 & 2453 & 3459 & 5251 & 4141 \\
NPC [\$] & 658,092 & 234,219 & 310,362 & 184,253 & 164,048 \\
Internal rate of return [\%] & - & 22.8 & 23.1 & 17.4 & 24.2 \\
LCOE [\$/kWh] & 0.644 & 0.229 & 0.304 & 0.18 & 0.16 \\
Simple payback period [years] & - & 4.6 & 3.96 & 6.5 & 4.5 \\
\hline
\end{tabular}

The system D1, which was the base case with the diesel generators as the only power source, had the highest net present cost (NPC) and levelized cost of electricity (LCOE) owing to the continuous operation of the diesel generators to 
meet the energy demand. This leads to an extremely high fuel consumption throughout the year. Also, there was no payback period or internal rate of return for this since it does not have any cash inflow against the investment.

The systems D2 and D3 contain the same configuration except for the fact that system D3 incorporates Vanadium flow redox batteries as compared to the Tesla Powerwall 2.0 lithium-ion batteries in system D2. The difference in the NPC was due to the high cost of the flow battery. It can be also noted that the NPC and the cost of electricity drastically drop as a wind turbine, photovoltaic and storage are added to the design configuration. There was a drop of $75 \%$ in the NPC and LCOE of the best-case combined system as compared to the diesel-only system.

It can be seen the design D5 was the best optimum solution among all the selected candidate systems since this system had the lowest NPC and LCOE. Additionally, the renewable energy fraction appears to be as high as $83.13 \%$.

The renewable energy penetration (Ren. Fraction [\%]) of a region was based on different factors such as the availability of solar irradiation and wind speed throughout the day. HOMER Pro was set to have a minimum percentage of renewable energy production and the energy demand of the houses was also loaded for simulation. When the simulation was running, it carried out several numbers of iterations based on the combination of factors mentioned above and provides multiple numbers of feasible solutions. Based on the constraint to minimize the net present cost as well as the payback period, the optimum feasible solution chosen was the one satisfying all these constraints.

The schematic of the design is shown in Figure 14.

The microgrid under consideration consists of a photovoltaic array and wind turbines combined with a battery energy storage system and a diesel generator to account for intervals during peak demand and/or periods of low sunshine and/or low wind speeds as shown in Table 4. Although the storage systems have a high initial cost as compared to a diesel generator, they have zero operational cost whereas the diesel generator consumes fuel hourly. Another reason for using a storage system in the microgrid was to minimize the use of the diesel generators thereby reducing the emission of harmful gases. The simulations were constrained such that there was no load unmet and that there was some additional to account for any sudden excess load.

Operational strategies [9]

The working strategies of the system were as follows:

- During the time of normal loads, hybrid resources such as PV and wind turbines will serve the load demand. The battery will get charged when there is excess energy produced by the system. If the batteries are $100 \%$ charged, the excess energy produced will either be dumped or diverted to help the energy demand of other houses.

- The diesel generator will supply for peak demand for periods of low wind speed and low sunshine. 


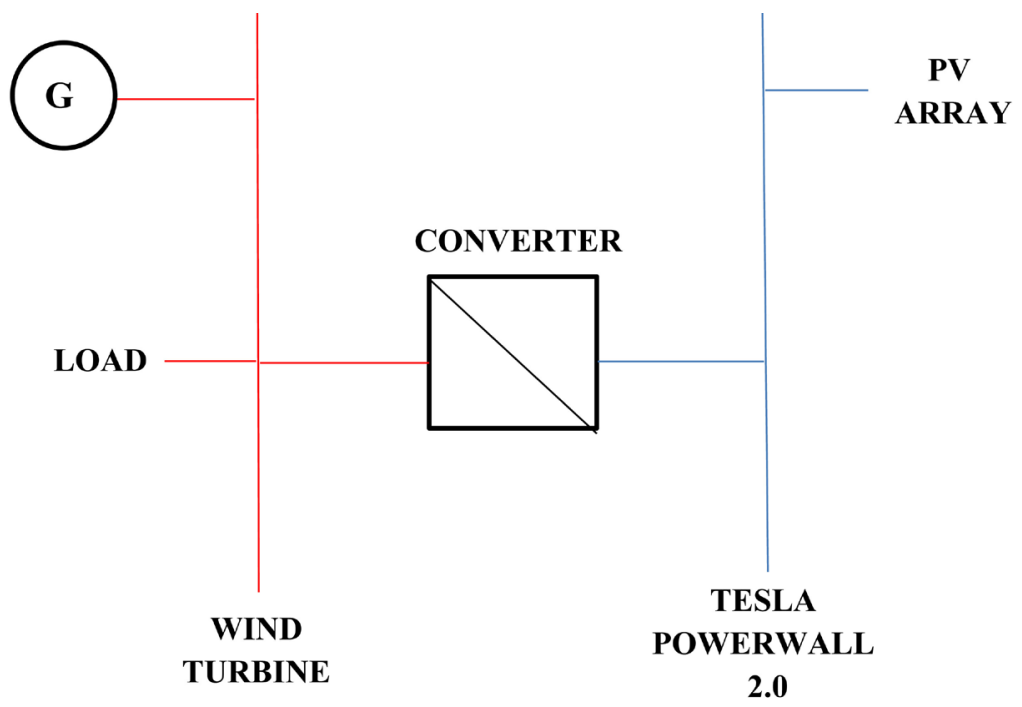

Figure 14. Schematic of the microgrid under consideration [8].

Table 4. Cost summary.

\begin{tabular}{ccccccc}
\hline Component & Capital [\$] & Replacement [\$] & O\&M [\$] & Fuel [\$] & Salvage [\$] & Total [\$] \\
\hline Diesel gen. & 17,000 & 0 & 6896 & 42,822 & 522 & 67,240 \\
PV Array & 7799 & 0 & 5966 & 0 & 0 & 13,765 \\
Wind & 37,000 & 0 & 4847 & 0 & 0 & 41,847 \\
Battery & 19,500 & 17,227 & 0 & 0 & 2335 & 39,062 \\
Converter & 5836 & 2476 & 0 & 0 & 466 & 8778 \\
System & 87,136 & 19,703 & 17,710 & 42,822 & 3324 & 170,695 \\
\hline
\end{tabular}

\section{Sensitivity analysis}

A sensitivity analysis was performed for the system considering the fluctuation in fuel prices and the general impact on the design of the system. The values considered were $\$ 0.80 /$ litre, $\$ 0.90 /$ litre, $\$ 1.00 /$ litre, $\$ 1.10 /$ litre, and $\$ 1.20 /$ litre. As expected, as the fuel price increases, a steady increase in the net present cost of the system occurred. It was also noted that the size of the photovoltaic array increases with an increase in the cost of the fuel. This was reasonable since the sensitivity tool was trying to trade the increase in the cost of the fuel by increasing the renewable energy fraction of the system (Table 5).

\section{Emission levels}

It is important to consider the intensity of harmful emissions from all the systems as we head towards a fully decarbonized world. Figure 15 illustrates the difference in emission levels of all the system designs. The system D2 possesses the least amount of emission levels followed by D3 and D5. The reduction in the emission levels by the islanded hybrid systems was quite significant.

The time series, shown in Figure 16, provides a summary of different energy sources meeting the energy demand during various times of the year. The hybrid system was observed covering most of the load demand throughout the year. 
Table 5. Sensitivity analysis of diesel fuel prices.

\begin{tabular}{cccccccc}
$\begin{array}{c}\text { Diesel Fuel Price } \\
\text { [\$/litre] }\end{array}$ & PV Array [kW] & \multicolumn{1}{l}{ Wind [no.s] } & Diesel Gen/Fuel [kW] & Battery [no.s] & Converter [kW] & NPC [\$] & Ren. Fraction [\%] \\
\hline $\mathbf{0 . 8 0}$ & 13.15 & 5 & 34 & 3 & 19.45 & 164.1 & 83.1 \\
$\mathbf{0} .90$ & 13.20 & 5 & 34 & 3 & 19.23 & 170.2 & 83.0 \\
1.00 & 13.20 & 5 & 34 & 3 & 18.84 & 176.40 & 83.3 \\
1.10 & 14.45 & 5 & 34 & 3 & 19.12 & 182.50 & 83.5 \\
1.20 & 14.40 & 5 & 34 & 3 & 19.11 & 188.4 & 83.4 \\
\hline
\end{tabular}

\section{Emission levels}

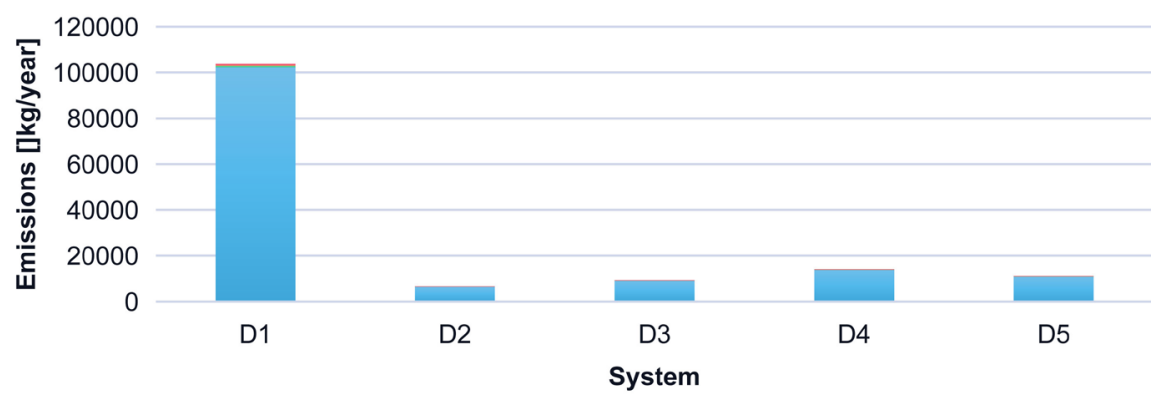
- Particulate Matter
Carbon Dioxide
Carbon Monoxide
- Unburned Hydrocarbons $\square$ Sulfur Dioxide
- Nitrogen Oxides

Figure 15. Emission levels from different systems.

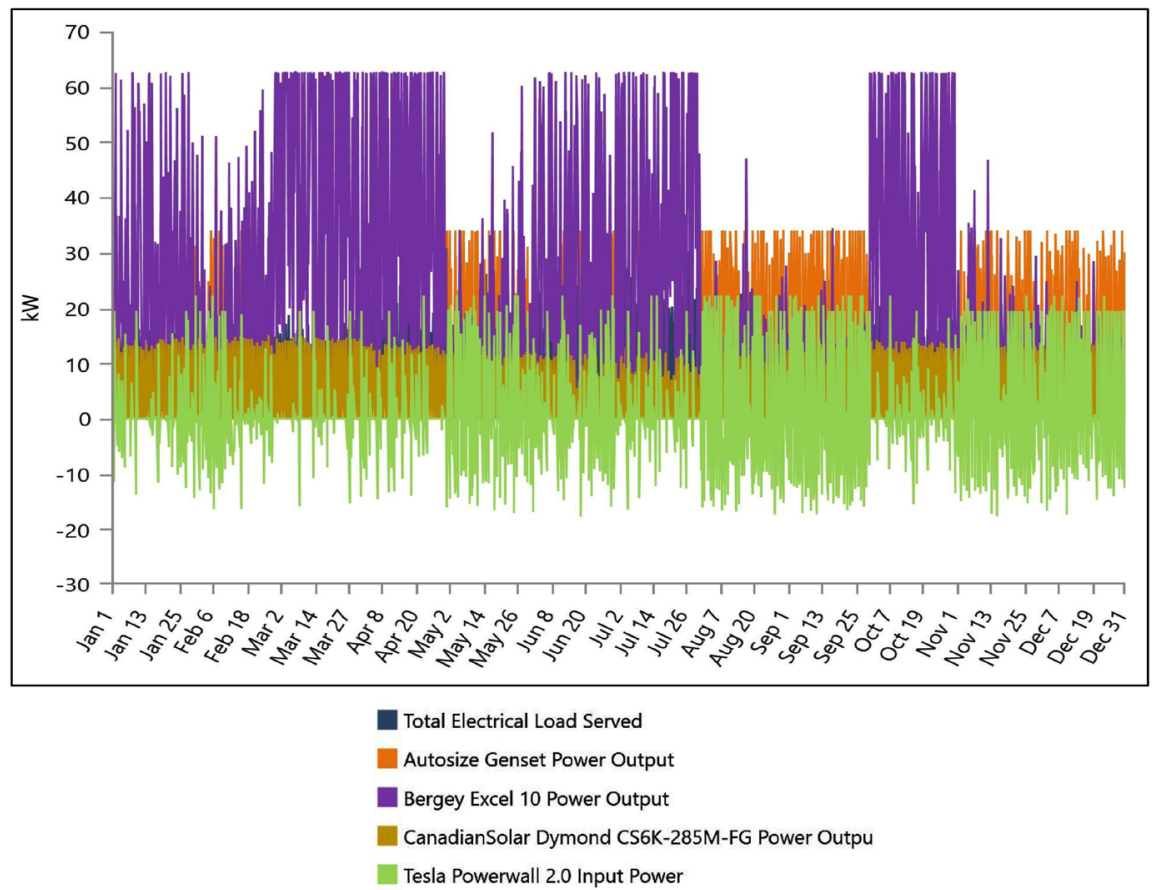

Figure 16. Time series chart for load and output.

Reading the data maps

The data maps shown in Figures 17-19 are interpreted by reading the gradient 


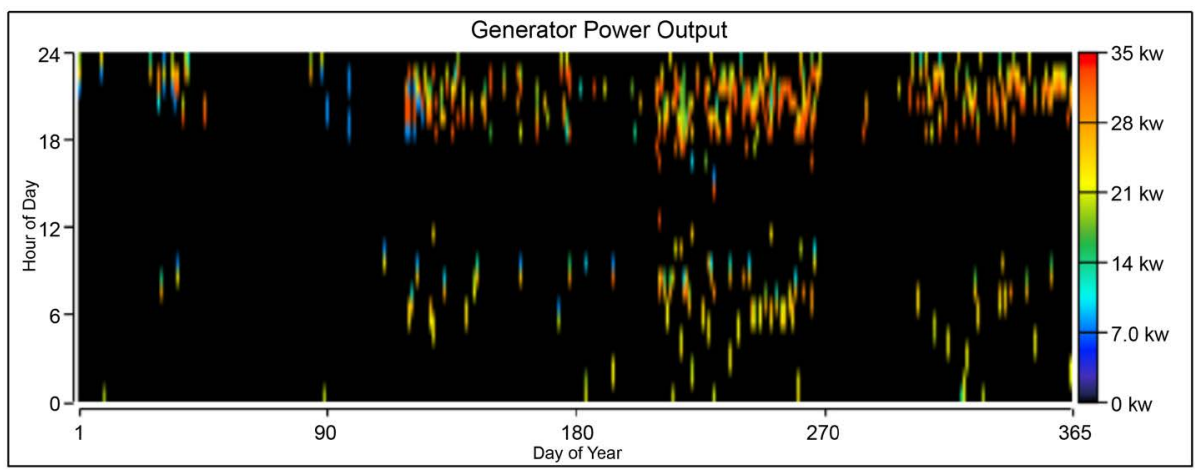

Figure 17. Generator power output.

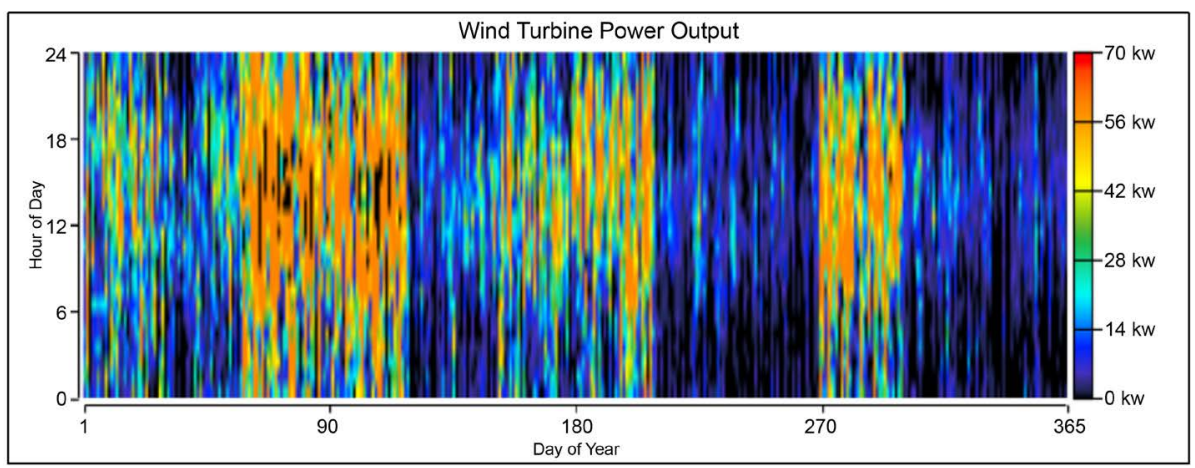

Figure 18. Wind turbine power.

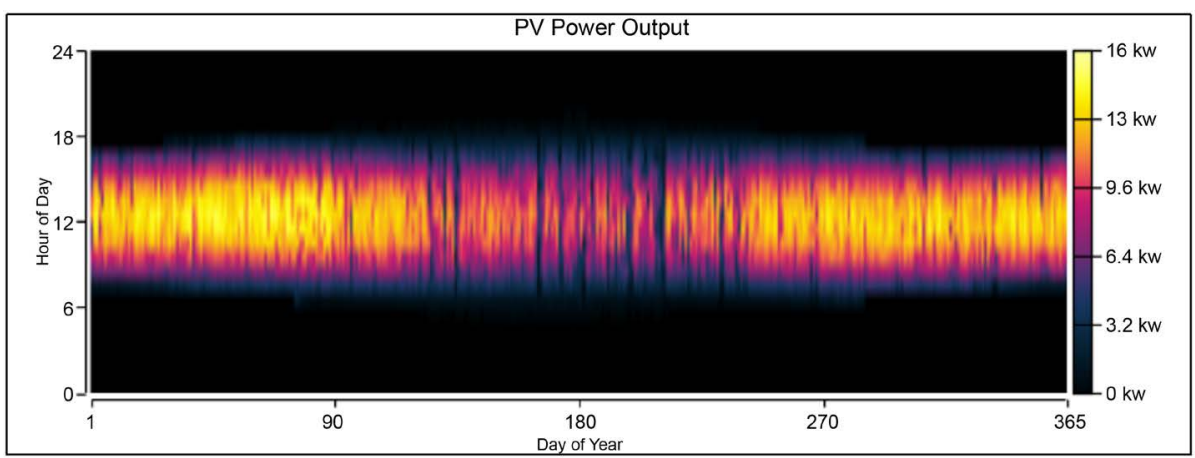

Figure 19. PV power output.

color bars alongside the plot. The cooler colors (dark colors) represent the lower value of the variable in the plot, whereas the warm colors (vivid colors) represent higher values of the variable. For example, the black color after the evening hours, i.e. after 5 pm until next morning 9 am, represents zero PV output. We can observe a gradual increase in the PV output after 9 am which is represented by the change from darker colors to vivid colors during the day.

The data maps (Dmap) in the figures above provide further details on the specific time of use of the load and system power output during the day throughout the year. The generator seemed to operate significantly more during the summer months when the wind speed was not significant enough. It was significant that resulted in the minimum use of the diesel generator throughout the year. This 
was because of the operational strategy of the microgrid system. The batteries can be seen to supply power mostly during the nighttime. As expected, the PV output peaked during the noon hours and was observed to operate from 9 am to $5 \mathrm{pm}$ during all the months. From observation of the simulation, it was concluded that the hybrid energy sources actually complement one another.

\section{Future Expansion}

As far as the future scope of the current microgrid study is concerned, Tohatchi appears to be near the natural gas processing plants as well as natural gas pipelines as shown in Figure 20. The location of a natural gas access point in the pipeline near the community could make the replacement of the diesel generators with natural gas generators more viable financially as well as environmentally.

The natural gas distribution system spans over a network of 3 million miles all over the United States along with 1.5 million miles of local low-pressure distribution lines. The implementation of natural gas could considerably improve the resiliency of the microgrid since natural gas can be stored on a large scale. As an alternative to diesel fuel, it also reduces the emission levels of the system by $78 \%$. Unlike, PV and wind, the natural gas grid could be readily integrated into the main grid. Generally, natural gas-fired microgrids can meet the energy demand of the community easily and at competitive prices. Figure 21 provides a comparison of the emission levels between diesel and natural gas.

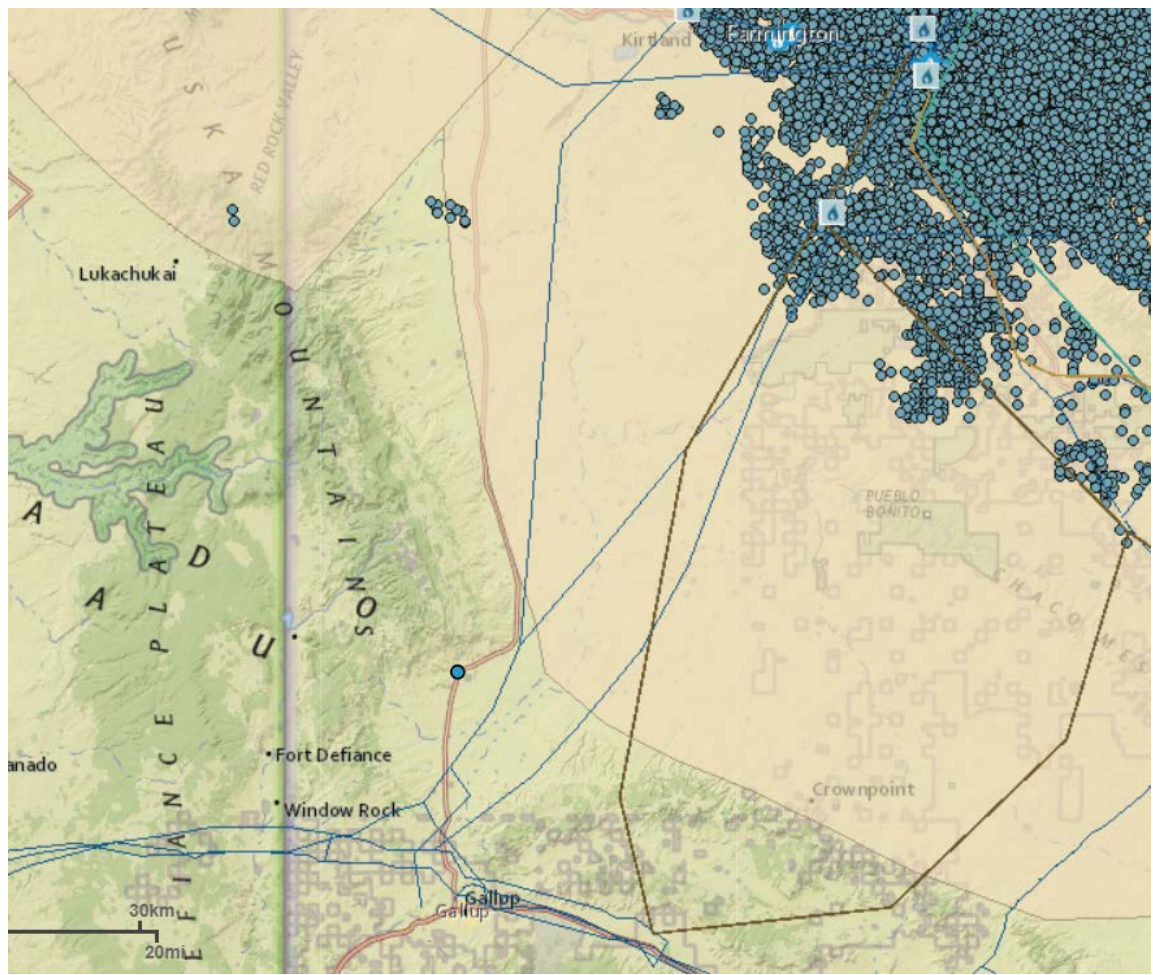

Figure 20. Natural gas resource map [10]. Natural Gas Pipeline Natural Gas Processing Plant. 


\section{Emission levels}

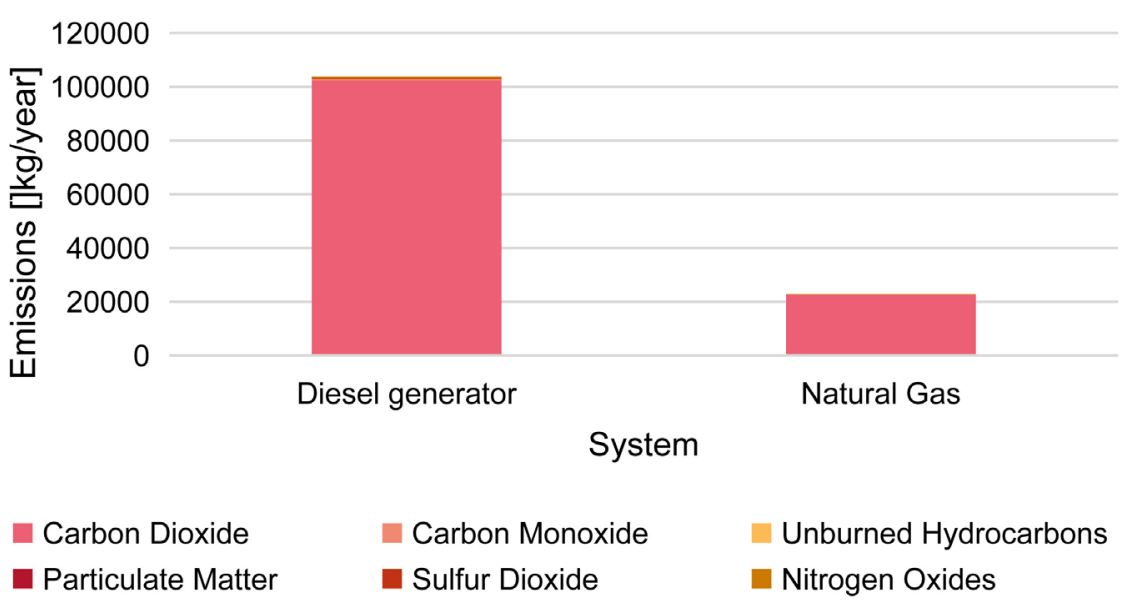

Figure 21. Comparison of emission levels between diesel generator and natural gas generator.

\section{Conclusions}

The purpose of this study was to conduct a feasibility analysis of an islanded microgrid in Tohatchi and find an optimum system that could serve the community in providing reliable, sustainable electricity while also reducing their carbon footprint and helping them solve their electricity needs. The NPC, and the LCOE, were the two crucial economic factors considered for this study. Through the analysis, the system with PV, wind turbines, battery, and a diesel generator was found to have the lowest LCOE and NPC. There was a reduction of $75 \%$ in the costs of the system as compared to the diesel-only base case. This combined system additionally provided minimum emission levels and, overall, was considered technologically viable for implementation. However, for this project to be more economically viable, financial support from the government bodies could help in the realization of this project. Moreover, the detection of access points in the natural gas pipelines near the community could further boost the resiliency of the system while also reducing the costs as well as the emission levels of the system.

The analysis also suggested that the integration of renewable energy using microgrids to help the access of energy for rural areas was possible. The process could very well be extended to the other communities in the Navajo Nation by considering the wind and solar resources present at that location.

\section{Conflicts of Interest}

The authors declare no conflicts of interest regarding the publication of this paper.

\section{References}

[1] Vernacchia, J. (2017) Understanding Microgrid and Energy Storage Feasibility Stu- 
dies. Microgrid 2017 Conference, EATON, Boston, 8 November 2017.

[2] Three Phases in Successfully Designing Microgrid Projects.

https://microgridnews.com/three-phases-in-designing-successful-microgrid-projects

[3] Giraldez, J., et al. (2018) Phase I Microgrid Cost Study: Data Collection and Analysis of Microgrid Costs in the United States. Technical Report, NREL/TP-5D00-67821. https://doi.org/10.2172/1477589

[4] HOMER Energy: HOMER Pro. https://www.homerenergy.com/

[5] Wind Energy Factsheet. http://css.umich.edu/factsheets/wind-energy-factsheet

[6] National Oceanic and Atmospheric Administration (NOAA). https://www.noaa.gov/

[7] Lim, T.M., et al. (2015) Advances in Membrane and Stack Design of Redox Flow Batteries (RBFs) for Medium and Large-Scale Energy Storage. Nanyang Technological University, Singapore. https://doi.org/10.1016/b978-1-78242-013-2.00014-5

[8] Abdilahi, A.M., et al. (2014) Feasibility Study of Renewable Energy-Based Microgrid System in Somaliland's Urban Centers. Renewable and Sustainable Energy Reviews, 40, 1048-1059. https://doi.org/10.1016/j.rser.2014.07.150

[9] Das, H.S., et al. (2016) Feasibility Analysis of a Standalone PV/Wind/Battery Hybrid Energy System for Rural Bangladesh. International Journal of Renewable Energy Research, 6, 402-412.

[10] United States Energy Information Administration (EIA). https://www.eia.gov/ 